\title{
Effect of number of irrelevant dimensions with ten concept types on the attribute identification task in the selection mode with exemplar and non-exemplar start cards
}

\author{
LEONARD M. GIAMBRA, Miami University, Oxford, Ohio \\ 45056
}

The purpose of this study was to determine the effect of increasing the number of irrelevant dimensions (IR) for 10 concept types with two types of start cards under conditions of the selection mode. The results indicated $(a)$ a directly proportional relationship between the relative conceptual difficulty under IIR and the increase in conceptual difficulty under 2IR; and (b) least difficulty under IIR with exemplar start cards and equal difficulty for both start cards under $2 I R$.

Haygood \& Stevenson (1967) documented and demonstrated the decremental effect of an increase in the number of irrelevant dimensions (IR) in the learning of simple (also called affirmational), conjunctive, inclusive disjunctive, and conditional concepts; furthermore, they demonstrated an interaction of conceptual type and IR which had the form of an increased decremental effect for increased IR for the more difficult conceptual types. No information was provided regarding the concepts of negation, alternate denial, joint denial, exclusion, exclusive disjunction and bicondition which represent the remaining conceptual types possible with two relevant dimensions (Neisser \& Weene, 1962; Haygood \& Bourne, 1965). Kepros \& Bourne (1966) found no differential increase in difficulty between the conjunctive and the biconditional concepts. Haygood \& Stevenson (1967) also demonstrated that the decremental and interaction effect of increased IR occurred not only in the attribute-identification task but also in the rule-learning and complete-learning tasks (see Haygood \& Bourne, 1965).

All previous studies of IR have been within the context of the reception mode and have ignored the selection mode. In. the reception mode $S$ receives the stimulus instances in the order and of a kind entirely determined by $E$ while in the selection mode $S$ selects the stimulus instances he desires, usually with all instances of the stimulus universe before him. Thus in the selection mode $S$ is an active solicitor of information while in the reception mode $S$ is a passive receptor. The difference in the role of $S$ in the two modes may moderate the effect of increased IR. The studies of Laughlin \& Jordan (1967) and Laughlin (1968) found behavior in the selection mode different from the reception mode with respect to the relative difficulty of the conditional and the biconditional concept types.

Another characteristic of previous studies of the effects of increased IR is that all concept problems were begun with exemplars of the concept; therefore the generality of the decremental effect of increased IR under conditions of starting concept problems with nonexemplars remains open to question. Beginning a problem with a nonexemplar increases the difficulty of a concept attainment problem for conjunctive type concepts and decreases the difficulty for disjunctive type concepts (Bruner, Goodnow, \& Austin, 1956); hence there may be an interaction between IR and type of start card. Thus the purpose of the present study was to explore the effect of IR on problem difficulty in the selection mode with the attribute identification task with 10 conceptual types and two types of start cards.

\section{METHOD}

The experimental design was a 2 by 2 by 2 by 10 factorial with two sex groups, two types of start cards (exemplar or nonexemplar), two levels of IR ( 1 or 2 ), and 10 types of concepts. There were three Ss per cell for a total of 240 all of whom were students at Miami University.

Each $\mathbf{S}$ had the entire stimulus universe before him; eight stimulus instances (randomly arranged) representing all possible combinations of three binary dimensions for 1 IR and 16 instances (randomly arranged) representing all possible combinations of four binary dimensions for 2 IR. Each S was read the instructions, given two practice problems, and then presented with six test problems. The instructions described the dimensions of the stimulus universe, the concept type, and the number of relevant dimensions as well as the procedure. It was pointed out that the same concept type would prevail throughout the experimental session. The test procedure followed this order: (a) E began each problem by pointing out the appropriate start card along with its status as an exemplar or nonexemplar (start cards were randomly chosen for each problem); (b) $\mathrm{S}$ then selected another stimulus instance indicating to $E$ whether he believed it to be an exemplar or nonexemplar; (c) $E$ then revealed the nature of the instance selected by $S$; (d) $S$ then verbally guessed the concept by stating the relevant dimensions combined according to the rule of the concept (an example might be "red one and not green 2 " in the case of the exclusion concept). Steps (b) through (d) were repeated until the concept was guessed correctly on four consecutive trials or if the time exceeded $15 \mathrm{~min}$ or if trials exceeded 20 and $\mathrm{S}$ was not in criterion sequence. The task was $S$ paced and the instructions simply indicated that $S$ was to identify the concept emphasizing neither speed nor accuracy. Every aspect of the procedure was recorded.

\section{RESULTS AND DISCUSSION}

Analyses of variance were performed using three dependent measures: time per trial, trials per problem, errors per problem. Number IR produced a significant effect, $p<.01$, on all three measures: $F(1,160)=39.86,56.74$, and 36.83 , respectively. On all measures this effect took the form of an increase with increased IR. Type Concept also produced a significant effect, $p<.01$, on all three measures: $F(9,160)=20.10,17.16$, and 5.94 , respectively. Table 1 contains the means for each of the concept types with each of the three dependent measures. The most conspicuous aspect of the Type Concept effect was the relative ease of the biconditional concept and the relative difficulty of the conditional concept. Supporting this also was the finding that $29.9 \%$ of conditional concept problems went unsolved and $2.1 \%$ of biconditional concept problems were unsolved. (Over the whole experiment the per cent unsolved was $7.6 \%$.) Laughlin \& Jordan (1967) and Laughlin (1968) found a similar effect while Neisser \& Weene (1962) found the inverse. Differences between this study, the Laughlin studies, and Neisser and Weene were that Neisser and Weene used (a) the reception mode, (b) the complete-learning task, and (c) $50 \%$ nonexemplars- $25 \%$ nonexemplars were used in this study for the conditional concept and 50\% for the biconditional concept. The results of a study by Giambra (1968) which replicated the Neisser and Weene study using the selection mode and $22 \%$ 
Table 1

Time per Trial, Trials per Problem, and Errors per Problem for 10 Concept Types under One and Two Irrelevant Dimensions

\begin{tabular}{|c|c|c|c|c|c|c|c|c|c|c|c|c|}
\hline \multirow[b]{2}{*}{ Type of Concept } & \multicolumn{4}{|c|}{ Time per Trial (min) } & \multicolumn{4}{|c|}{ Trials per Problem } & \multicolumn{4}{|c|}{ Errors per Problem } \\
\hline & I IR & 2 IR & Mean & $\begin{array}{l}\text { Differ- } \\
\text { ence }\end{array}$ & $1 \mathrm{IR}$ & 2 IR & Mean & $\begin{array}{l}\text { Differ- } \\
\text { ence }\end{array}$ & $1 \mathrm{IR}$ & 2 IR & Mean & $\begin{array}{l}\text { Differ- } \\
\text { ence }\end{array}$ \\
\hline Affirmation & .27 & .29 & .28 & .02 & 5.40 & 5.71 & 5.55 & .31 & 1.11 & 1.16 & 1.13 & .05 \\
\hline Negation & .30 & .36 & .33 & .06 & 5.38 & 7.99 & 6.68 & 2.61 & 1.04 & 1.79 & 1.41 & .75 \\
\hline Conjunction & .32 & .44 & .38 & .12 & 5.39 & 7.39 & 6.39 & 2.00 & 1.50 & 2.76 & 2.13 & 1.26 \\
\hline Alternate Denial & .49 & .71 & .60 & .22 & 7.03 & 11.62 & 9.32 & 4.59 & 1.46 & 3.43 & 2.34 & 1.97 \\
\hline Inclusive Disjunction & .37 & .44 & .40 & .07 & 8.02 & 9.66 & 9.34 & 1.64 & 1.70 & 2.64 & 2.17 & .94 \\
\hline Joint Denial & .38 & .49 & .43 & .11 & 6.00 & 9.23 & 7.61 & 3.23 & 1.85 & 3.25 & 2.55 & 1.40 \\
\hline Conditional & .52 & .87 & .69 & .35 & 11.31 & 13.64 & 12.47 & 2.33 & 2.59 & 3.16 & 2.87 & .57 \\
\hline Exlusion & .47 & .52 & .49 & .05 & 6.04 & 10.60 & 8.32 & 4.56 & 2.01 & $4.10^{\mathrm{a}}$ & 3.05 & 2.09 \\
\hline Biconditional & .36 & .50 & .43 & .14 & 9.13 & 7.70 & 8.81 & -1.43 & 1.52 & 1.68 & 1.60 & .16 \\
\hline Exlusive Disjunction & .64 & .94 & .79 & .30 & 7.35 & 9.54 & 8.45 & 2.19 & 1.58 & 2.27 & 1.92 & .69 \\
\hline
\end{tabular}

aDue to one $S$ who had 13 errors per problem, mean without him was 3.24 errors.

nonexemplars for the conditional concept support the hypothesis of a task-based difference as the probable cause of the reversal of the relative difficulty of the conditional and biconditional concepts in this study. Thus the added rule-learning aspect of the complete learning task increased the difficulty of the biconditional concept much more than for the conditional concept. The Type Concept by Type Start Card interaction was significant, $\mathrm{p}<.01$, for the measures of trials per problem, $F(9,160)=4.72$, and errors per problem, $F(9,160)=4.46$, and was due to an increase for nonexemplar start cards with conjunctive type concepts and an increase for exemplar start cards with disjunctive type concepts. This would be expected since nonexemplar start cards provide less information for $\mathrm{S}$ than exemplars when conjunctive type concepts are to be identified while the converse is true when disjunctive type concepts are to be identified. Number IR interacted with this interaction, $F(9,160)=2.71, p<.01$, for the trial per problem measure; the pattern of increase for two IR was difference for exemplar and nonexemplar start cards. No explanation was possible for either pattern or their difference.

Of major interest in this study were the significant interactions of IR with Type Start Card and Type Concept. The IR by Type Start Card interaction was significant only for time per trial, $F(1,160)=5.63, p<.05$. This interaction was due primarily to quick times per trial with exemplar start cards under one IR and essentially the same times per trial for two IR regardless of start card. Thus the type of start card only effects performance in the easier task of one IR. The IR by Type Concept interaction significantly effected time per trial, $F(9,160)=2.43, \quad p<.05$, and trials per problem, $F(9,160)=3.85, p<.01$. Table 1 portrays this interaction. A correlation of $.80(\mathrm{p}<.01, \mathrm{~N}=10)$ was calculated across the 10 concepts between the mean time per trial for one IR and the difference in the group mean time per trial as IR increased from one to two. (The correlation for the trials per problem was -.26 and for errors per problem was $.23, \mathrm{p}>.05, \mathrm{~N}=10$.) Thus a significant proportional relationship existed between the difficulty of conceptual type and the degree of decremental effect produced by increased IR only for the time per trial dependent measure. Hence, for the measure time per trial (and to a lesser degree for the measure errors per problem) Haygood and Stevenson's findings were extended to 10 conceptual types and to the selection mode showing that the IR by Type Concept interaction does not break down under the reduced memory and active information solicition characteristics of the selection mode.

\section{REFERENCES}

BRUNER, J. S., GOODNOW, J. J., \& AUSTIN, G. A. A study of thinking. New York: Wiley, 1956.

GIAMBRA, L. M. Concept identification behavior and selection strategies as a function of sex, type start card, type concept, and number irrelevant dimensions. Ann Arbor, Mich., University Microfilm, 1968, No. (unassigned).

HAYGOOD, R. C., \& BOURNE, L. E., Jr. Attribute- and rule-learning aspects of conceptual behavior. Psychological Review, 1965, 72, 175-195.

HAYGOOD, R. C., \& STEVENSON, M. Effects of number of irrelevant dimensions in nonconjunctive concept learning. Journal of Experimental Psychology, 1967, 74, 302-304.

KEPROS, P. G., \& BOURNE, L. E., JR. Identification of biconditional concepts: Effects of number of relevant dimensions. Canadian Journal of Psychology, 1966, 20, 198-207.

LAUGHLIN, P. R. Focusing strategy for eight concept rules. Journal of Experimental Psychology, 1968, 77, 661-669.

LAUGHLIN, P. R., \& JORDAN, R. M. Selection strategies in conjunctive, disjunctive, and biconditional concept attainment. Journal of Experimental Psychology, 1967, 188-193.

NEISSER, U., \& WEENE, P. Hierarchies in concept attainment. Journal of Experimental Psychology, 1962, 64, 282-290.

(Continued from page 74)

RAPOPORT, A., \& CHAMMAH, A. M. Prisoner's dilemma. Ann Arbor: University of Michigan Press, 1965.

STEELE, M. W., \& TEDESCHI, J. T. Matrix indices and mixed-motive games. Journal of Conflict Resolution, 1967, 11, 198-205.

TEDESCHI, J. T., HORAI, J., LINDSKOLD, S., \& GAHAGAN, J. The effects of threat and conflict intensity on compliance and communication. Proceedings of the 76th Annual Convention of the APA, 1968, 399-400.

\section{NOTES}

1. This research was supported, in part, by NIH Grant No. SB26 FR07022-02 912 1902, made to the University of Miami.

2. The authors wish to thank Donald Lewis for designing and constructing the apparatus, Bruce Weber for devising a program for generating the data used in the analyses, and Peg Tedeschi for analyzing the data. 